Justin lohanne Siy Rabo, MD

Allan B. Carpella, MD

Eutrapio S. Guevara Jr., MD

Joel A. Romualdez, MD

Department of Otolaryngology

Head and Neck Surgery

Saint Luke's Medical Center
Correspondence: Dr. Allan B. Carpella

Department of Otolaryngology

Head and Neck Surgery

St. Luke's Medical Center

279 E. Rodriguez Ave., Quezon City 1102

Philippines

Phone: (632) 7275543

Fax: (632) $7231199(\mathrm{H})$

Email: slmcearnosethroat@yahoo.com

The authors declare that this represents original material that is not being considered for publication elsewhere in full or in part, in print or electronic media; that the manuscript has been read and approved by all the authors, that the requirements for authorship have been met by each authors, and that each author believes that the manuscript represents honest work.

Disclosures: The authors signed disclosures that there are no financial or other (including personal) relationships, intellectual passion, political or religious beliefs, and institutional affiliations that might lead to a conflict of interest

Presented at the Clinical Case Report Contest (1st Place), Philippine Society of Otolaryngology-Head and Neck Surgery, Menarini Office, 4/F W Bldg. 11th Ave. cor. 28th St. Bonifacio High St. BGC Taguig, June 2, 2015

\section{(ब) $\Theta$}

\section{Mandibular Ameloblastoma with Lung Metastasis 10 Years after Resection}

\begin{abstract}
Objective: To present a case of mandibular ameloblastoma with pulmonary metastasis after ten years and discuss the possible pathophysiology, diagnostic and therapeutic options.
\end{abstract}

\section{Methods:}

\author{
Design: Case Report \\ Setting: Tertiary Private Hospital \\ Patient: One
}

Results: A 27-year-old woman diagnosed with follicular variant ameloblastoma underwent left segmental mandibulectomy with iliac bone reconstruction in 2004. The titanium plates were removed in 2008 because of a recurrent orocutaneous fistula. She was apparently well until 2014, when she complained of intermittent, non-radiating, sharp and piercing, right upper back pains. Work-ups revealed multiple bilateral lung nodules. A CT scan-guided percutaneous needle biopsy of the right upper lung nodule revealed metastatic ameloblastoma. Opting for observation instead of chemoradiation, she remains asymptomatic on regular follow-ups with medical oncology, pulmonary medicine and otorhinolaryngology.

Conclusion: Though benign, ameloblastoma has a high propensity for local invasion and may metastasize. It is difficult to predict metastasis, even with adequate treatment of the primary lesion. There is no standard protocol to prevent or detect metastatic ameloblastoma, but regular and close follow up may ensure early diagnosis.

Keywords: ameloblastoma, metastatic ameloblastoma, lung metastasis, follicular type ameloblastoma, odontogenic tumor

Ameloblastoma is a benign, slow-growing odontogenic tumor with locally aggressive behavior and a high recurrence rate in $50 \%-72 \%$ of cases. ${ }^{1}$ It accounts for $1 \%$ of all tumors and cysts in the jaw, with the angle of the mandible as the most common primary site affected. Since over half of resected tumors recur, many consider ameloblastoma locally malignant but not metastasizing. ${ }^{2}$ Metastases, however, have been reported to occur in up to $2 \% .{ }^{3}$ Over $80 \%$ of such metastases involve the lungs, followed by cervical lymph nodes (15\%-28\%), vertebrae, and less 
frequently, the skull, liver, parotid gland, diaphragm, and brain. ${ }^{4}$

We present a case of a mandibular ameloblastoma with lung metastasis and discuss the possible pathophysiology, diagnostic and therapeutic options.

\section{CASE REPORT}

A 27-year-old woman with no known co-morbidities consulted in 2004 for a gradually enlarging left mandibular mass since 2002. Wedge biopsy revealed ameloblastoma and a segmental mandibulectomy with iliac bone reconstruction was performed that same year. The final histopathology revealed ameloblastoma, follicular variant. A postoperative orocutaneous fistula was repaired twice, in November and December 2004. She remained apparently well (with normal routine annual chest x-rays) on regular follow-ups until 2008, when the fistula recurred. The titanium plates and screws were removed, and the fistula was repaired. Her condition allegedly improved and she was lost to follow-up thereafter.

She was reportedly well until 2014, 10 years after the first surgery, when she noted intermittent, non-radiating, sharp and piercing, right upper back pains with no associated symptoms. Bilateral multiple pulmonary nodules were seen on chest X-Rays. Her otorhinolaryngologic and chest examinations were unremarkable with symmetrical chest expansion, no lag, and and clear, equal breath sounds. Considering an infectious process versus metastasis from a primary neoplasm, a high resolution chest CT scan with contrast showed "multiple varied-sized, non-calcified, non-enhancing pulmonary and pleural-based nodules/masses in both lungs." The largest on the right was located in the anterior basal segment of the right lower lobe measuring approximately $2.2 \times 3.3 \mathrm{~cm}$. (Figure 1) The findings were compatible with metastases.

A CT scan-guided percutaneous needle biopsy of right upper lung nodule yielded"highly cellular smears with spindle cells, scattered singly and in tight and loose clusters admixed with atypical epithelial cells, set in a bloody background," (Figure 2) with chondromyxoid stroma in some clusters. The cell block showed "stellate reticulum-like cells in clusters with peripheral palisading columnar cells, some exhibiting reverse polarization." (Figure 3) Final histopathology results were signed out as "cytomorphologic findings consistent with metastatic ameloblastoma."

Plain CT scans revealed no recurrence of the osseous tumor in the left mandibular body. (Figure 4) She was given oral analgesics for the back pain, and offered chemotherapy and radiotherapy. She opted to observe her condition with regular monitoring instead, since she was then asymptomatic. She is currently well and is being monitored by medical oncology, pulmonary medicine and otorhinolaryngology.

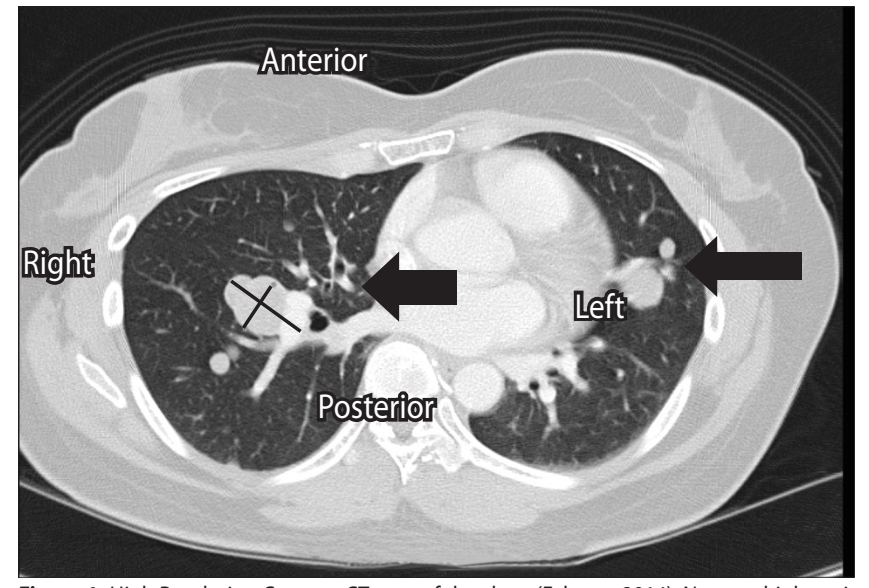

Figure 1. High Resolution Contrast CT scan of the chest (Febuary 2014). Note multiple varisized non-calcified pulmonary and pleural-based nodules/masses randomly scattered in both lungs. The largest on the right is located in the anterior basal segment of the right lower lobe measuring approximately $2.2 \times 3.3 \mathrm{~cm}$ (thick arrow), while the largest on the left is noted in the inferior lingula measuring $1.9 \times 1.9 \mathrm{~cm}$ (thin arrow).

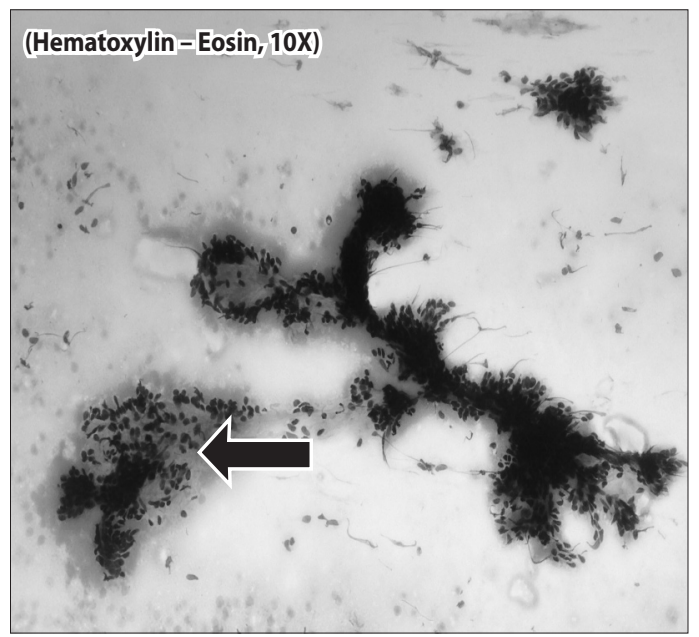

A. Low Power View, 10X

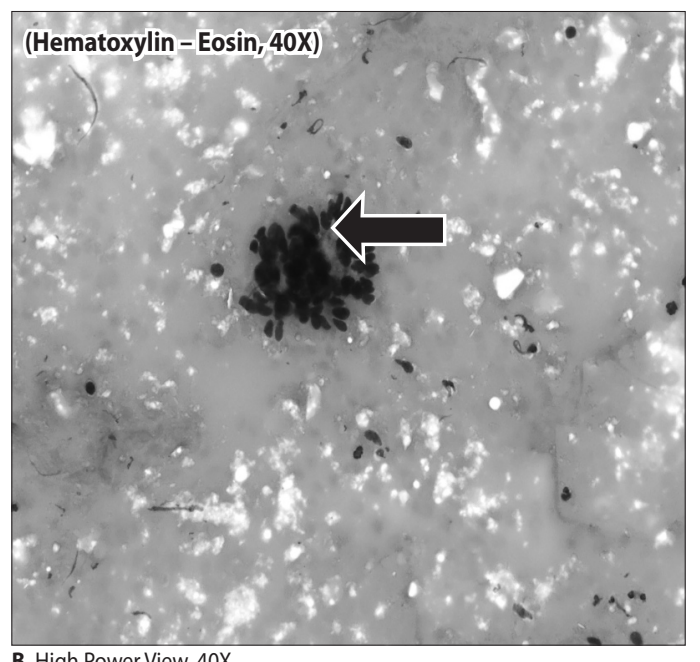

B. High Power View, 40X

Figure 2. Histopathologic slides of CT-guided needle biopsy of pulmonary nodules, Hematoxylin - Eosin, showing clusters of spindle cells and epithelial cells in both low power (A) and high power (B) views 
CASE REPORTS

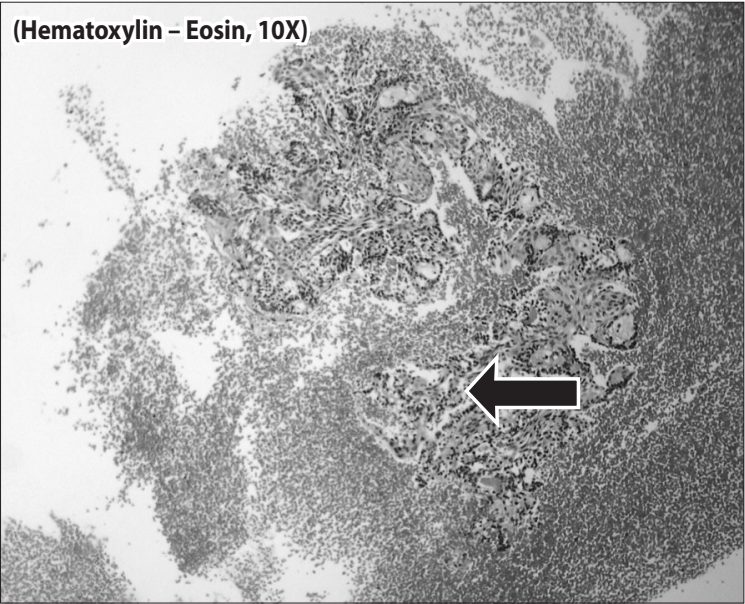

A. Low Power View, 10X

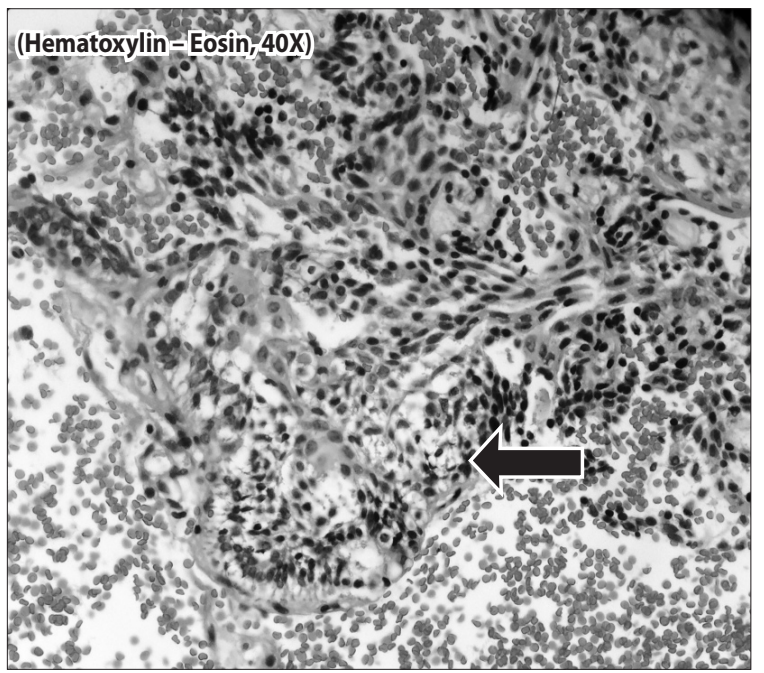

B. High Power View, 40X

Figure 3. Histopathologic slides of cell block, Hematoxylin - Eosin, showing clusters of stellate reticulate-like cells with peripheral palisading columnar cells in both low power (A) and high power (B) views.

\section{DISCUSSION}

Of all swellings of the oral cavity, $9 \%$ are odontogenic tumors, and ameloblastoma accounts for $1 \%$ of lesions within this group. ${ }^{5}$ Ameloblastoma frequently arises from rests of primitive dental lamina located in the gingiva, in the alveolar bone above the teeth apices, and in the follicular walls of unerupted teeth. ${ }^{6}$ The most common primary site affected is the mandible, specifically, its angle. ${ }^{5}$ Occurring with equal frequency in both sexes, usually between the third and fifth decade of life, it is asymptomatic in most cases, and presents only as an incidental finding. ${ }^{5}$ Histological classification subdivides it into follicular, plexiform, acanthomatous and granular ameloblastoma. ${ }^{5}$

The World Health Organization (WHO) defines metastatic ameloblastoma as an ameloblastoma which metastasizes, with the

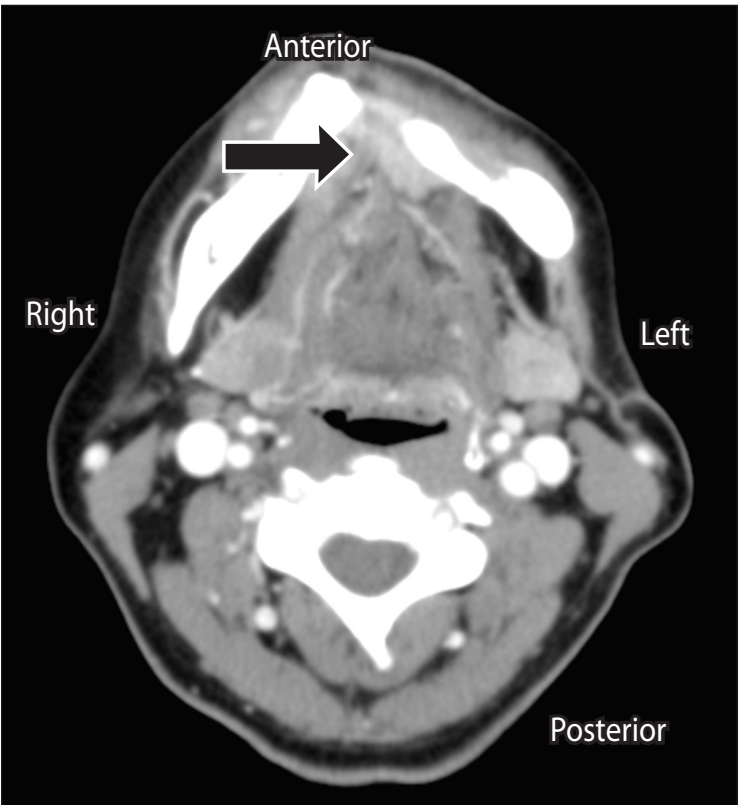

Figure 4. Plain CT Scan (June 2014) Surgical defects are seen in the LEFT mandibular body (arrow) likely relating to the previous surgical site. There are no signs for recurrence of an osseous tumor.

primary and metastatic tissues demonstrating benign histological features; whereas an ameloblastic carcinoma exhibits malignant features, such as cellular atypia and mitosis. ${ }^{7}$ Metastatic ameloblastoma is rare with about 70 reported cases. ${ }^{8}$ Both the gnathic primary tumor and the metastatic foci have typical morphologies of a benign ameloblastoma with bland nuclei and absent to rare mitosis. ${ }^{8}$ This histopathologic features of metastatic ameloblastoma are consistent with our case, although atypical epthithelial cells were noted, this is a focal type of atypia which can sometimes also be seen in benign cases. $^{9}$

There is no definite pathophysiologic basis for how ameloblastoma can metastasize, but three routes are mentioned in the literature: hematogenous, lymphatic, and by aspiration..$^{10}$ Another possible mode of metastasis is tumor implantation during surgical procedures. ${ }^{11}$ Other studies theorized that multiple surgeries can significantly increase the risk of metastases, and that curettage opens pathways for dissemination of the tumor to adjacent structures, which may lead to surgical seeding. ${ }^{12}$ In our case, metastasis could have been due to two routes: first, hematogenous since the tumor was diffusely scattered in both lung fields; and second by aspiration from the endotracheal tube during her previous surgery. Because the exact mechanism of metastasis remains unknown, only speculations can be made.

We are not aware of any report on the specific signs and symptoms 


\section{CASE REPORTS}

of metastatic ameloblastoma, and most cases of ameloblastoma are asymptomatic. In this case, our patient only presented with an intermittent, non-radiating, sharp and piercing, right upper back pains. Diagnosis is usually due to incidental findings on CT scan or chest $x$-ray, which prompts further work-up. The diagnosis of metastatic ameloblastoma can only be made in retrospect; hence, it is difficult to predict which cases would metastasize and which would not. There may be a role for routine annual chest x-rays (which in our patient's case were a social service requirement), but as also seen in our case, were negative for five years.

The prognosis of metastatic ameloblastoma is poor. Henderson et al. reported a median survival of approximately 2 years after the detection of metastasis. ${ }^{10}$ The mean survival of patients who did not receive any treatment or who were treated with multi-agent chemotherapy was 1.1 years. ${ }^{13}$ Another study that reviewed 29 cases of ameloblastoma with lung metastases concluded that median survival was longer at around 6.6 years when surgical resection was performed compared to other treatment modalities or close monitoring. ${ }^{13}$

Because of the rarity of metastatic ameloblastoma, the clinical course and appropriate treatment are not yet established. Close observation, surgical resection, and chemotherapy/radiotherapy are treatment options. ${ }^{14}$ Adequate treatment of the primary lesion is the most important element in the management of ameloblastoma.

For isolated and discretelung metastatic ameloblastoma, particularly in the lung periphery, treatment may be via open thoracotomy and wedge resection, or by lobotomy, depending on the number of lesions and their location. ${ }^{4}$ Significant resection, with preservation of as much viable lung tissue as possible, is the treatment of choice. ${ }^{4}$ Surgical resection was not an option for our patient since multiple nodules were noted in both lungs, as it is best considered if the lesion is solitary and peripherally located.

Other treatment modalities, such as chemotherapy and radiotherapy, are yet to be defined. Chemotherapy has shown variable results, in some cases achieving only a reduction in tumor size, but producing no effective improvement in most cases. ${ }^{10}$ Currently there is no single-agent or combination chemotherapy regimen that can be recommended for palliation in patients with unresectable metastases. However, there are some reports showing metastatic ameloblastoma to the lungs that responded well to carboplatin/paclitaxel, suggesting benefits for systemic treatment in cases with inoperable disease. ${ }^{15}$ Radiotherapy has been recommended for inoperable metastatic deposits, but because the response is unpredictable, it should be used only for palliative care. ${ }^{16}$ Because the tumor is unresectable and the patient has no signs of disease progression, her choice to forego chemoradiation in favor of close monitoring and symptomatic relief of symptoms is the best treatment option at the moment.

Though benign, ameloblastoma has a high propensity for local invasion and may rarely metastasize, most commonly to the lungs. It is difficult to predict metastasis, even with adequate treatment of the primary lesion, as there is no sign or symptom specific for metastatic ameloblastoma. There is no standard protocol to prevent or detect metastatic ameloblastoma, but regular and close follow up and monitoring, even years after primary resection, may ensure early diagnosis.

\section{REFERENCES}

1. Ciment LM, Ciment AJ. Malignant ameloblastoma metastatic to the lungs 29 years after primary resection: A case report. Chest. 2002 Apr; 121(4):1359-1361.

2. Inoue N, Shimojyo M, Iwai H, Ohtsuki H, Yasumizu R, Shintaku M, et al. Malignant ameloblastoma with pulmonary metastasis and hypercalcemia. Am J Clin Pathol. 1988 Oct; 90 (4):474-481.

3. Mathew S, Rappaport K, Ali SZ, Busseniers AE, Rosenthal DL. Ameloblastoma: cytologic findings and literature review. Acta Cytol. 1997 Jul-Aug; 41(4):955-960.

4. Newman L, Howells GL, Coghlan KM, DiBiase A, Williams DM. Malignant ameloblastoma revisited. Br J Oral Maxillofac Surg. 1995 Feb; 33(1):47-50.

5. Lee SK, Kim YS, Current concepts and Occurrence of Epithelial Odontogenic Tumors: I. Ameloblastoma and Adenomatoid Odontogenic Tumor. Korean J Pathol. 2013 Jun; 47(3): 191202.

6. Adekeye EO. Ameloblastoma of the jaws: A survey of 109 Nigerian patients. J Oral Surg. 1980 Jan; 38(1):36-41.

7. Gilijamse $M$, Leemans $C R$, Winters $H A H$, Schulten EAJM, van der Waal I. Metastasizing ameloblastoma. Int J Oral Maxillofac. Surg. 2007 May; 36(5): 462-464.

8. Atun JM, Carante J. Metastasizing Ameloblastoma. Philipp J Otolaryngol Head Neck Surg. 2015 Jul-Dec; 30 (2): 67-68.

9. Rosai J. Roasai and Ackerman's Surgiacl Pathology $10^{\text {th }}$ Edition. St Louis: Elsevier- Health Science Division: 2011. P. 276-278.

10. Henderson JM, Sonnet JR, Schlesinger C, Ord RA, Pulmonary metastasis of ameloblastoma: Case report and review of the literature. Oral Surg Oral Med Oral Pathol Oral Radiol Endod. 1999 Aug; 88(2):170-176.

11. Kunze E, Donath K, Luhr HG, Engelhardt W, De Vivie R. Biology of metastasizing ameloblastoma. Pathol Res Pract. 1985 Nov; 180(5):526-535.

12. Zwahlen RA, Gratz KW. Maxillary ameloblastomas: A review of the literature and of a 15-year database. J Craniomaxillofac Surg. 2002 Oct; 30(5):273- 279.

13. Laughlin EH. Metastasizing ameloblastoma. Cancer. 1989 Aug; 64(3):776-780.

14. Scannell J, Lees B, Hopper C. Can radiofrequency ablation be used as a treatment modality for the management of pulmonary Metastatic ameloblastoma? Radiol Case Rep. 2009; 4:249.

15. Grünwald V, Le Blanc S, Karstens JH, Weihkopf T, Kuske M, Ganser A, et al. Metastatic malignant ameloblastoma responding to chemotherapy with paclitaxel and carboplatin. Ann Oncol. 2001 Oct; 12(10):1489-91.

16. Georgakas I, Lazaridou M, Dimitrakopoulos I, Tilaveridis I, Sekouli A, Papakosta, D. et al. Pulmonary metastasis in a 65-year-oldman with mandibular ameloblastoma: a case report and review of the literature. J Oral Maxillofac Surg. 2012 May; 70(5):1109-1113. 